
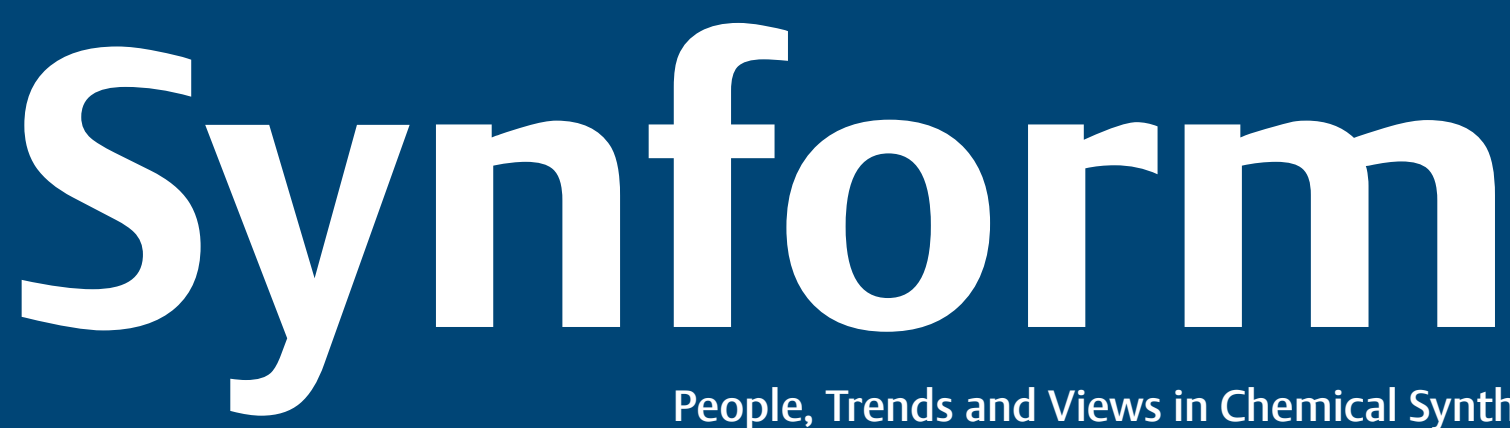

People, Trends and Views in Chemical Synthesis

\title{
$2017 / 09$
}

Arthur Michael (1853 - 1942): The Michael Addition Reaction

Article by D. E. Lewis and R. K. Dieringer

\section{Contact}

Your opinion about Synform is welcome, please correspond if you like:

marketing@thieme-chemistry.com
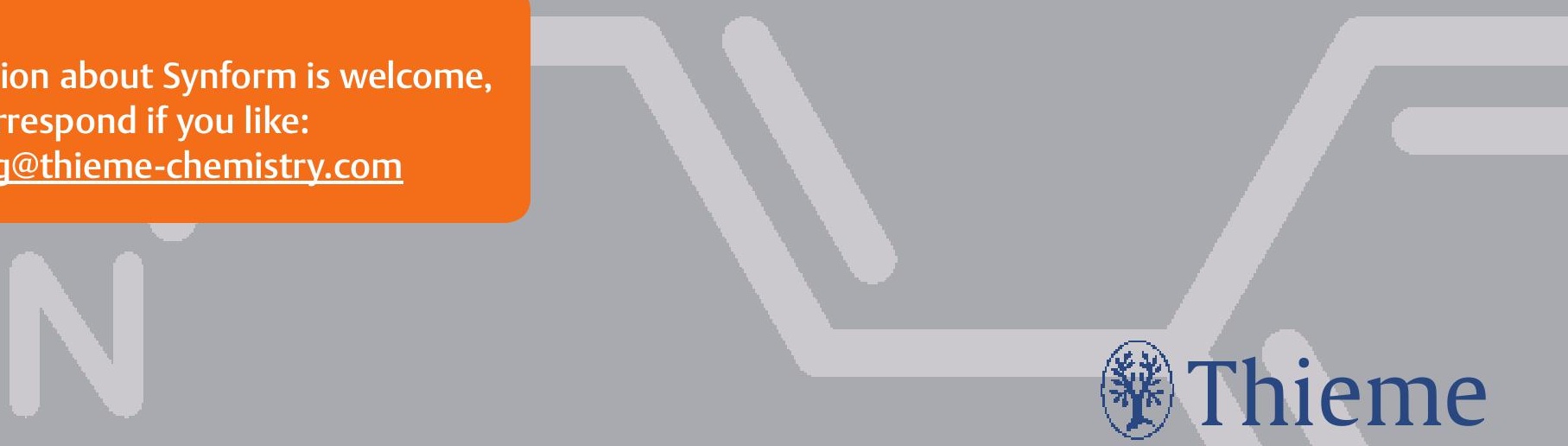


\section{Dear Readers,}

Sadly, summer holidays are already over for me. However, I have to confess that - although the weather is not so good, as one should expect in Scotland where the summer can easily last no longer than one or two days - I am really enjoying the very mild and sometimes even chilly temperatures, while most of the southern and central Europe is currently grilling and sweating in an infernal heatwave. No al fresco dinners and no sun tan here, that's for sure, but at least there is no risk of melting alive! Only one thing is really hot right now: it's this new SYNFORM issue! Actually, it's red hot because it is opened by a brand new editorial feature, authored by Professor David Lewis (University of Wisconsin-Eau Claire, USA): "Name Reaction Biography" (NRB), which is going to be published with a quarterly frequency. The first NRB article - co-authored by Rachael K. Dieringer - celebrates the $130^{\text {th }}$ anniversary of the Michael reaction with an entertaining and insightful biography of Arthur Michael, a giant of organic chemistry and a true trailblazer. We really hope you will enjoy this and the next NRB articles! The September issue continues with a contribution describing the progress towards the synthesis of archazolid recently reported by Gregory O'Neil (USA) and is followed by the automated oligosaccharide synthesis technology developed by Peter H. Seeberger (Germany). The third article covers the monumental work on the collective synthesis of indole alkaloids recently published by Yong Qin (P. R. of China), and the issue is completed by a Young Career Focus interview with Alexander J. Grenning (USA).

Enjoy your reading!

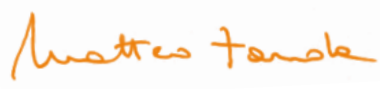

\section{In this issue}

Name Reaction Bio

Arthur Michael (1853-1942):

The Michael Addition Reaction

A142

SYNLETT Highlight

Synthesis of the $C_{1}-C_{23}$ Fragment of the Archazolids and Evidence for V-ATPase but not COX Inhibitory

Activity.

Literature Coverage

Automated Glycan Assembly Using the Glyconeer

2.1 Synthesizer

Literature Coverage

Collective Synthesis of Indole Alkaloids Enabled by Photoredox-Initiated Radical Cascade Reactions

Young Career Focus

Young Career Focus: Professor Alexander J. Grenning

(University of Florida, USA)

Coming soon. A160

\section{Contact}

If you have any questions or wish to send feedback, please write to Matteo Zanda at: synform@outlook.com 


\section{Arthur Michael (1853-1942): The Michael Addition Reaction}

The Michael reaction is now 130 years old, ${ }^{1}$ and its use has continued unabated since. ${ }^{2}$ As is so often the case, the chemist behind the reaction is not nearly as well known to chemists as the reaction itself. Despite several useful biographies of Michael, ${ }^{3}$ most organic chemists have little knowledge of his far-reaching work, or of the razor-sharp intellect that he used to great effect in criticizing the science of his contemporaries.

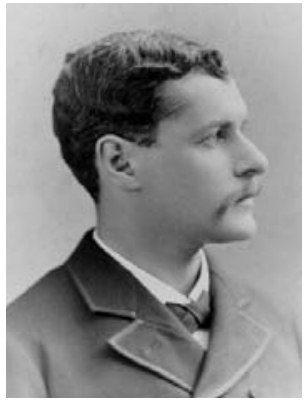

Arthur Michael (1853-1942) in 1886 (image courtesy of Tufts University archives)

Michael was born in Buffalo, New York, and attended classical school there, where he received private instruction in chemistry. His father, a well-off real-estate investor, encouraged his son's early love for chemistry, setting up a home laboratory for him and allowing him to conduct his own experiments there. However, toward the end of his teens he suffered a serious illness (brain fever, possibly scarlet fever), which eliminated his chances of entering Harvard College but allowed him to dabble in art and literature before returning to chemistry.

In 1871, he was admitted to Berlin University, where he studied in August Wilhelm von Hofmann's laboratory - despite not having the required chemistry background. After a year in Hofmann's laboratory, Michael continued his studies under Robert Bunsen at Heidelberg, where he strengthened his practical training. During this year Michael became the first to synthesize a natural glucoside, helicin. ${ }^{4}$ The method he used would become the standard synthetic route for this class of natural products.

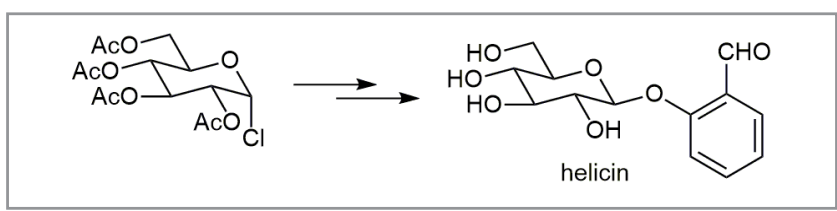

Figure 1
Two years later, he rejoined Hofmann at Berlin and continued his work there from 1875 to 1878. In 1879, Michael conducted research in Paris with Charles-Adolphe Wurtz, as well as in St. Petersburg with Mendeleev.

Michael returned to the United States in 1880, with considerable experience, but no formal degree. Even so, just has he had first been appointed to Hofmann's group without having satisfied all the requirements, he was appointed as an assistant in the chemical laboratory at Tufts College for a year before being appointed Professor of Chemistry there. He was awarded two honorary degrees from Tufts: the A. M. in 1882, and the Ph.D. in 1890.

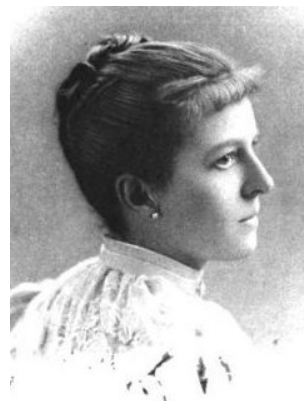

Helen Abbott Michael (1857-1904); Frontispiece to Studies in Plant and Organic Chemistry: And Literary Papers

In 1889, Michael married his student, Helen Cecilia DeSilver Abbott (1857-1904), an organic chemist herself, and one of the few women in the field. In addition, she was fully Michael's intellectual equal. After their marriage, the couple spent 18 months traveling around the world. Michael was an enthusiastic mountaineer, and climbed several alpine peaks, including the Matterhorn. After their return to the United States, Michael accepted the position of Head of the Chemical Laboratory at Clark University in Worcester, Massachusetts a position he had originally declined. After just one year at Clark, Michael moved to the Isle of Wight, where he set up a private laboratory. He worked in this laboratory for three years. He resumed his professorship at Tufts in 1894, and held this position until his retirement in 1907. Following his retirement, Michael set up a new private laboratory near Boston. In 1912, he was appointed Professor, without lecturing duties, at Harvard University. He retired from this position in 1936.

In 1887 Michael published the first of four papers with the title "Ueber die Addition von Natriumacetessig- und Natriummalonsaüreäthern zu den Aethern ungesättiger Säuren.” In this first report of what is now his eponymous reaction, Michael reported the addition of diethyl sodiomalonate and 
ethyl sodioacetatoacetate to ethyl cinnamate. Over the course of the next seven years, Michael and his students extended the reaction to a wide range of conjugated esters, including

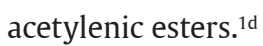

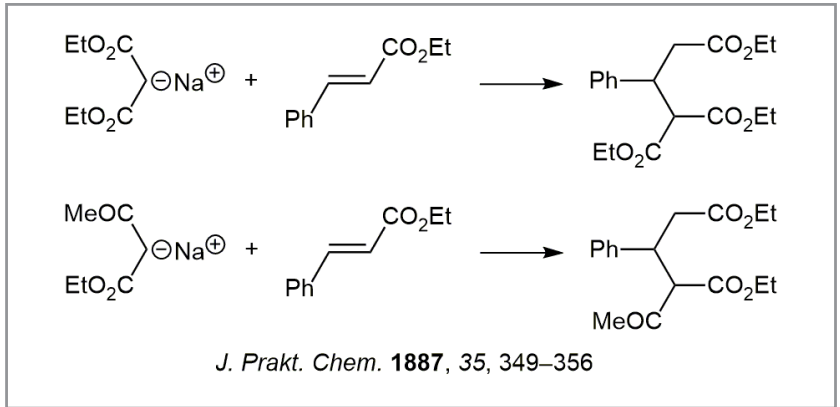

Scheme 1

The power of this relatively simple reaction has been demonstrated repeatedly since its discovery. In 1935, Rapson and Robinson demonstrated an extremely useful tandem Michael reaction, now known as the Robinson annulation (or annelation). ${ }^{5}$

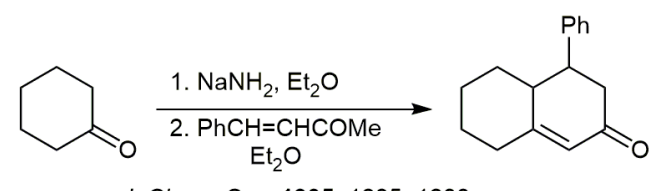

J. Chem. Soc. 1935, 1285-1288

Scheme 2

More recently, research on the Michael reaction has been focused on controlling stereochemistry in both the relative and the absolute sense, ${ }^{2 g-i}$ especially using chiral catalysts. The use of a chiral organocatalyst is nicely illustrated by Jørgensen's synthesis of $(S)$-warfarin using a $C_{2}$-pseudosymmetric chiral diamino acid, where the carboxy group is attached to the ring as either an $r$ or an $s$ pseudocenter of chirality. ${ }^{6}$

Although he is best remembered for the Michael addition reaction and its many derivatives, Michael's primary focus was actually the role of theory in organic chemistry. Working just after the great advances in organic structure and stereochemistry, he became a pioneer in physical chemistry and physical organic chemistry. As such, many of his most important contributions were as a critic of others' scientific work. He was highly respected as a very intuitive critic, if often ex-

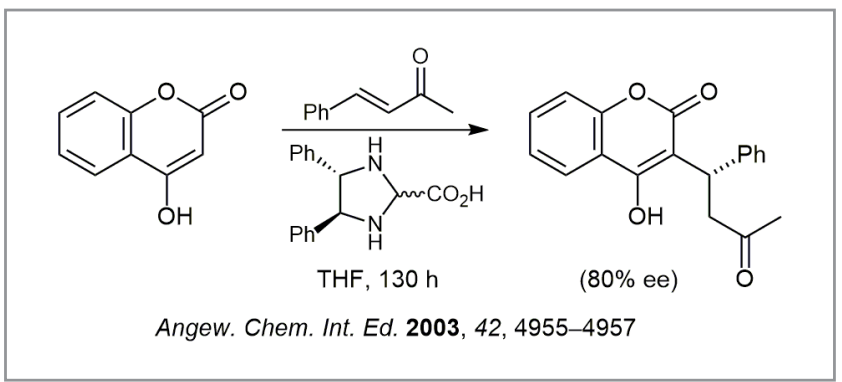

Scheme 3

cessively blunt in his criticism. His criticisms were usually so cogent that he was hard for others to ignore. When Kolbe, Lossen, Claus, and Fittig all raised questions about the first version of van't Hoff's theory, their critiques were not taken completely seriously, especially following Kolbe's infamous diatribe. ${ }^{7}$

Michael often took the persona of an outsider arguing with the mainstream ideas. He was never afraid to take a stance at odds with the rest of the chemical community. He had great confidence in his work and had no problem disagreeing with others. He helped to broaden the field of structural theory through his criticisms and research.

Michael's Harvard colleagues described him as "a powerful theorist, a keen critic, and a consummate experimentalist." His criticisms of van't Hoff's stereochemical theory, for example, were taken seriously - such an extensive, multipart critique could not be so easily dismissed. ${ }^{8}$ Michael's cogent arguments helped establish stereochemistry in organic chemistry. He also saw weakness in Wislicenus's theory that additions to unsaturated substances necessarily precede cis. Michael was driven by his general dislike of the mechanical aspects of stereochemical theory.

He lost his wife, Helen, to the influenza virus in 1904. He then retired from Tufts but continued to work in a private laboratory in Boston. In 1912 he was asked back to Harvard where he supervised graduate work until 1936 when he became emeritus. His love for research lasted until the day he died and with age he grew to enjoy gardening, a love for plants was something he and Helen both shared, as well as golf. He passed away at almost ninety years old in 1942 while wintering in Florida.

Throughout his life, Michael was an avid art collector; he was especially fond of ancient and medieval art. His collection grew over the course of the years to contain thousands of rare art pieces and objects. The friendship he developed with Ernest Fenollosa, an American art historian who specialized in Japanese art, led him to become fascinated with oriental art. 
Much of his collection was objects and pieces from the Orient. Upon his passing he donated his large collection of American silver to the Smithsonian Institution and the remainder of his collection to the Albright Art Gallery located in his hometown of Buffalo. Even though he loved children he never had any of his own and therefore gave the remainder of his sizable estate to Buffalo Institutes that cared for crippled, blind, and needy children.

He also had a great love for hiking and climbing mountains, taking a majority of his vacations among mountain ranges like the Alps, the Canadian Rockies, and the Selkirks. He was among the first group to ascend both Mount Lefroy and Mount Victoria between Alberta and British Columbia's borders. He was an alert, artistic, and brilliant person but he was also intensely private. Michael resented publicity of any kind, even denying awards due to the publicity they would draw. It can be believed that he never received the credit he was due but many that knew him believed he wouldn't have appreciated the attention. His intense dedication to organic chemistry was not done for accolades but for his love of organic chemistry. His career spanned the length of almost seven decades; he first became published at the age of twenty-three and had a great number of publications throughout his life, with his final publication appearing a few months after his death.

\section{REFERENCES}

(1) (a) A. Michael J. Prakt. Chem. 1887, 35, 349-356;

(b) A. Michael, P. C. Freer J. Prakt. Chem. 1891, 43, 390-395;

(c) A. Michael, O. Schulthess J. Prakt. Chem. 1892, 45, 55-63;

(d) A. Michael J. Prakt. Chem. 1894, 49, 20-25.

(2) Reviews: (a) E. D. Bergmann, D. Ginsburg, R. Pappo

Org. React. 1959, 10, 179-556; (b) M. Jung, In Comprehensive

Organic Synthesis, Vol. 4, M. Semmelhack, Ed., Pergamon: London, 1991, 1-67; (c) V. J. Lee, In Comprehensive Organic Synthesis, Vol. 4, M. Semmelhack, Ed., Pergamon: London, 1991, 69-137; (d) H. G. Schmaltz, In Comprehensive Organic Synthesis, Vol. 4, M. Semmelhack, Ed., Pergamon: London, 1991, 199-236; (e) R. D. Little, M. R. Masjedizadeh, O. Wallquist, J. I. Mcloughlin Org. React. 1995, 47, 315-552; (f) B. D. Mather, K. Viswanathan, K. M. Miller, T. E. Long Progr. Polym. Sci. 2006, 31, 487-531; (g) H. Pellisier Tetrahedron 2007, 63, 9267-9331; (h) Y. Zhang, W. Wang Catal. Sci. Technol. 2012, 42-53; (i) E. Reyes, U. Uria, J. L. Vicario, L. Carrillo Org. React. 2016, 90, 1-898.
(3) (a) A. B. Costa J. Chem. Educ. 1971, 48, 243-246;

(b) L. F. Fieser Arthur Michael, In Biogr. Mem. Natl. Acad. Sci., National Academy Press: Washington, D.C., 1975, 46, 330-366; (c) C. C. Gillispie Complete Dictionary of Scientific Biography, Charles Scribner \& Sons: Detroit, 2008;

(d) P. J. Ramberg Hist. Studies Phys. Biol. Sci. 1995, 26, 89-138;

(e) T. Tokoroyama Eur. J. Org. Chem. 2010, 2009-2016.

(4) A. Michael Ber. Dtsch. Chem. Ges. 1879, 12, 2260-2261;

(b) A. Michael Ber. Dtsch. Chem. Ges. 1882, 15, 1922-1925;

(c) A. Michael Am. Chem. J. 1879, 1, 305-312.

(5) (a) W. S. Rapson, R. Robinson J. Chem. Soc. 1935, 1285-

1288; (b) R. E. Gawley Synthesis 1976, 777-794.

(6) N. Halland, T. Hansen, K. A. Jørgensen Angew. Chem. Int. Ed. 2003, 42, 4955-4957.

(7) H. Kolbe J. Prakt. Chem. 1877, 15, 467-472.

(8) A. Michael J. Prakt. Chem. 1895, 52, 289-325.
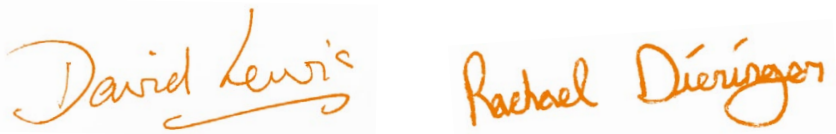


\title{
Synthesis of the $C_{1}-C_{23}$ Fragment of the Archazolids and Evidence for V-ATPase but not COX Inhibitory Activity
}

\author{
Synlett 2017, 28, 1101-1105
}

V-ATPase is an important anti-cancer target and archazolid natural products represent a promising starting point for the development of V-ATPase-based cancer therapies. Over the last few years, the intensity of cancer research involving archazolid natural products has increased, as evidenced by several recent studies demonstrating promising activity for these compounds against particularly lethal and aggressive types of cancer. This follows an increasing appreciation for the role of the vacuolar-type ATPase (V-ATPase) in cancer.

However, archazolids remain scarcely available, which has hindered their development as V-ATPase inhibitor therapeutics. "Only small quantities of archazolids are available from the natural source, and yet the vast majority of biological studies have utilized extracted and laboriously purified material. This argues for continuing efforts toward a more 'ideal' total synthesis," said Professor Gregory O’Neil from Western Washington University (USA). In a recent Synlett article, Professor O'Neil's group described what promises to be a highly efficient synthesis of the archazolids based on a convergent Stille coupling to construct the substituted $Z, Z, E$-conjugated triene unique to this class of compounds.

Professor O'Neil noted: "It is interesting that this reaction was only successful when using the 'eastern' fragment as the stannane and the 'western' fragment as the iodide (which we rationalize as being due to steric interactions during the oxidative addition step). Since tin and iodide groups are inter- changeable, the lesson here seems to be that it is prudent to investigate both coupling scenarios when attempting and/or encountering difficulties with complex Stille couplings."

The group's advanced archazolid intermediate displayed dose-dependent inhibition of the V-ATPase. "We were quite excited by the V-ATPase assay results obtained for our advanced fragment 1 , despite its modest activity ( 100 times less potent than the natural product), given the overall structural simplifications relative to the natural product," remarked Professor O'Neil. He continued: “The results make a further case for the $C_{7}-C_{15}$ region of the natural products being pharmacophorically relevant, and gives us a starting point for future SAR studies. It is also planned to scale up our synthesis of 1 to make this compound more widely available as a new tool for V-ATPase/cancer research."

Despite a computational suggestion that the compound would inhibit the cyclooxygenase (COX) enzyme, no COX inhibitory activity was measured.

"There are a number of interesting questions that have been raised by our COX inhibition results in light of the previous theoretical study," concluded Professor O'Neil. "For instance, does the inactivity of our compound arise from it being too large and/or because it lacks a carboxylic acid terminus? Are other factors such as binding entropies at play? These are all questions that we hope to address through synthesis."

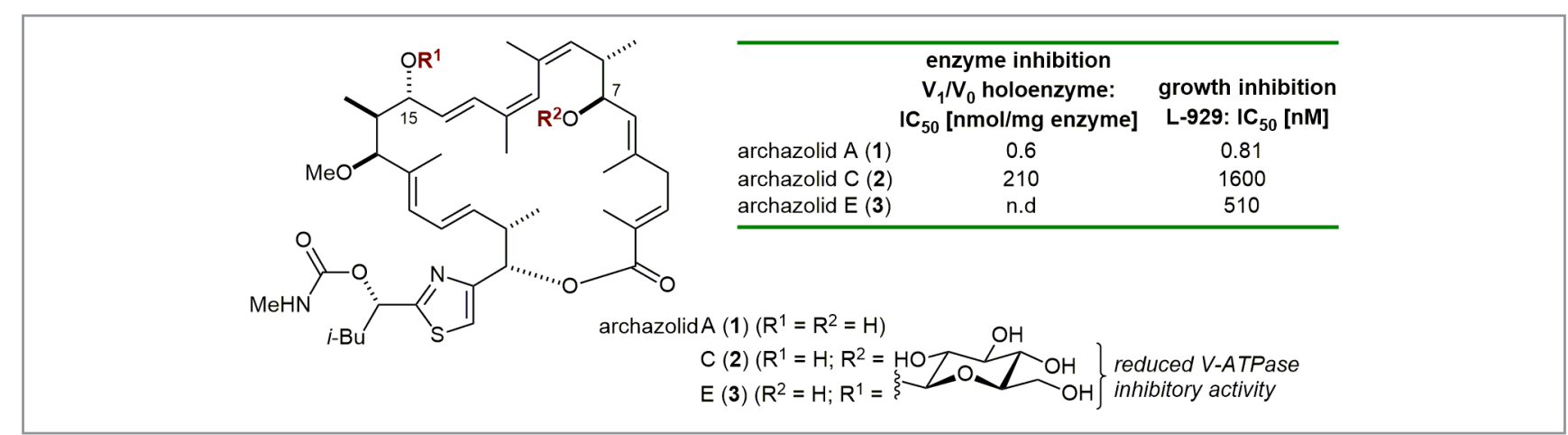

Figure 1 Structure of the archazolid natural products. Glycosylation at either the $C_{7}$ or $C_{15}$ hydroxyl significantly reduces their V-ATPase inhibitory activity, indicating that these two groups form important interactions with the enzyme. Interestingly, these same hydroxyls are connected by a Z,Z,E-conjugated triene unique to the archazolids. 


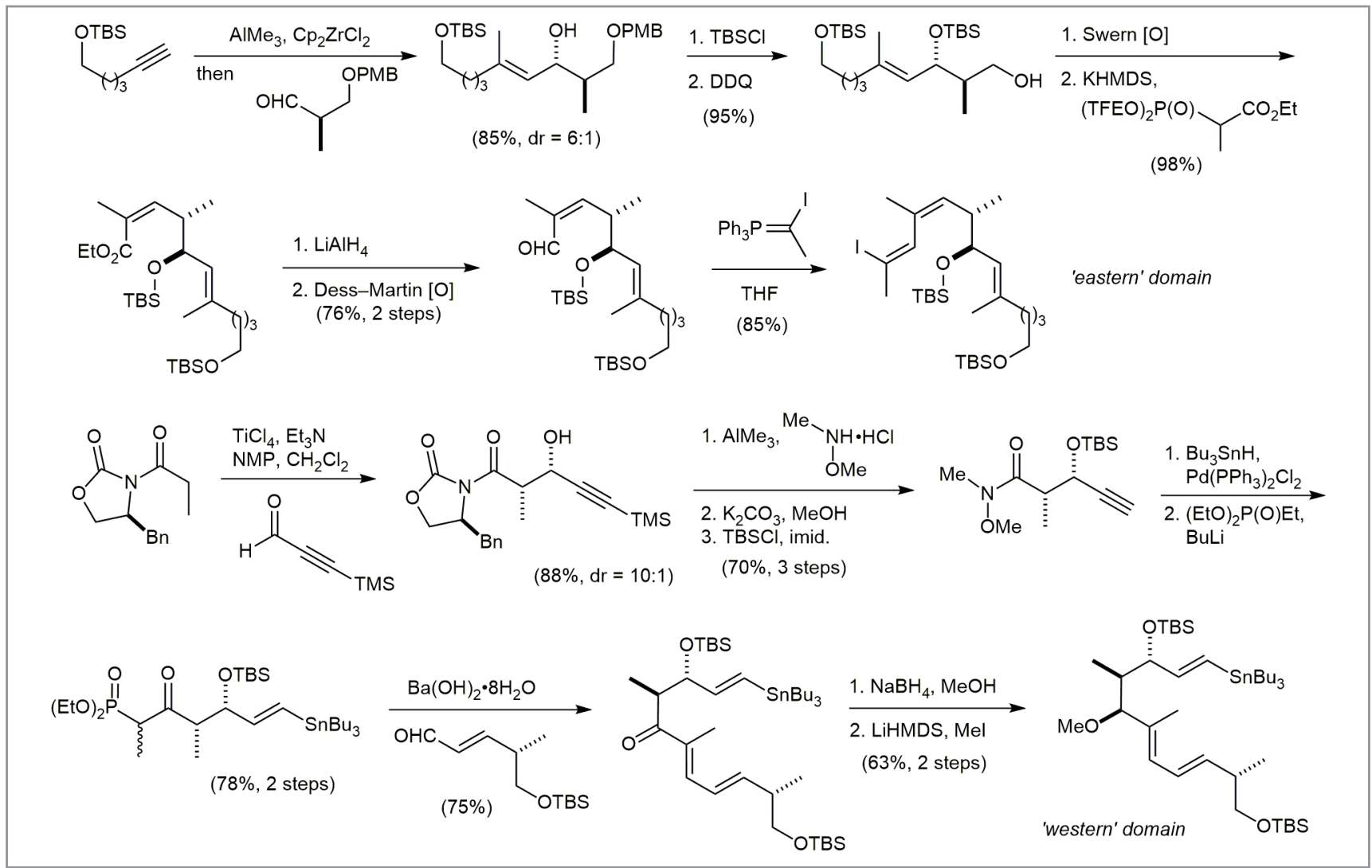

Scheme 1 Synthesis of the 'eastern' and 'western' domains of the archazolids

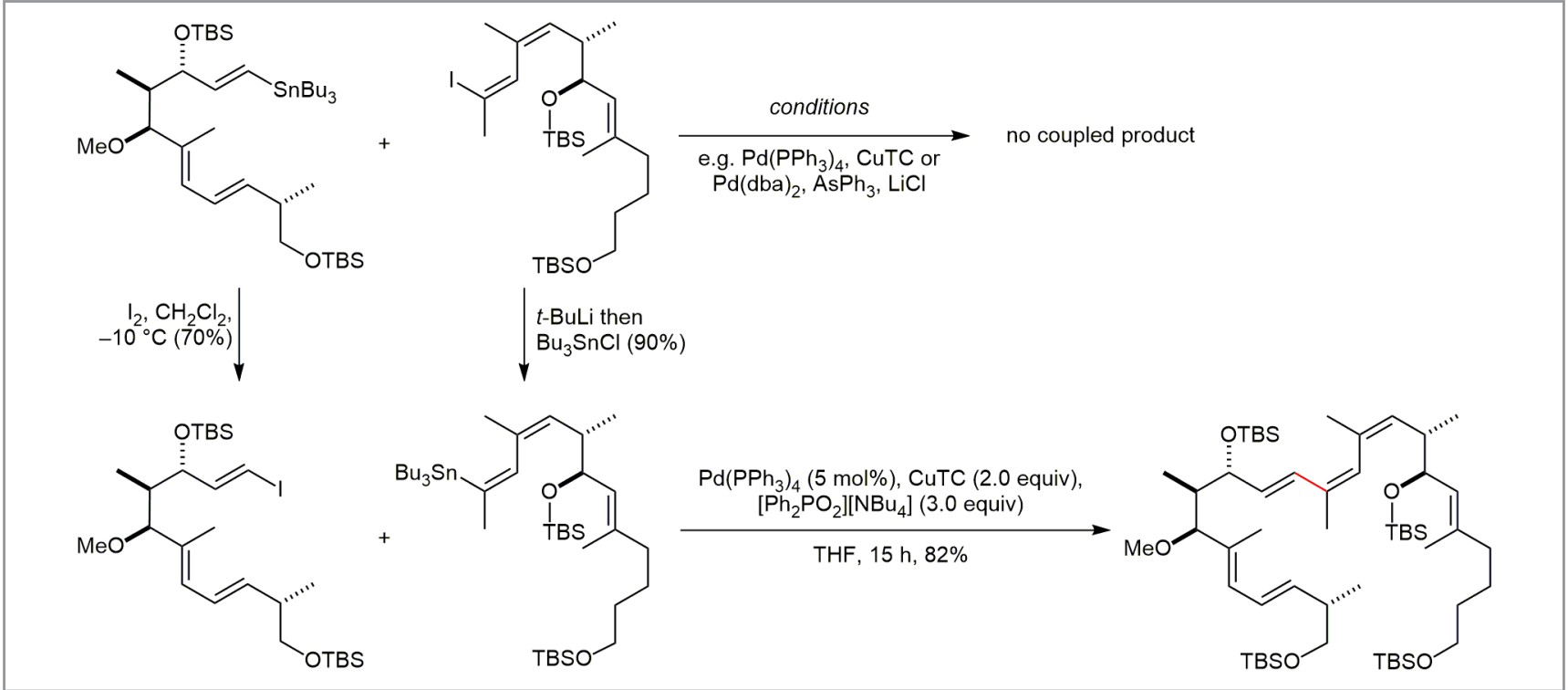

Scheme 2 Completion of the $C_{1}-C_{23}$ fragment (1) of the archazolids by a complex Stille coupling. First attempts using the 'western' stannane and 'eastern' iodide all failed. Switching the sense of organometallic/halide in these reactions led to success with the reaction. 

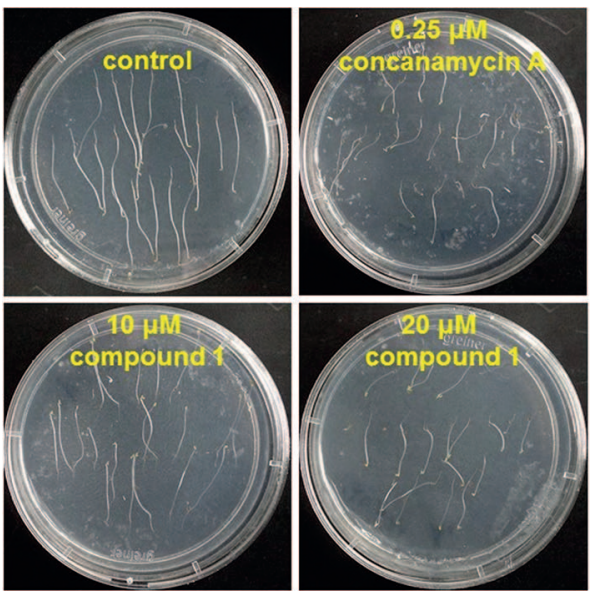<smiles>COC(/C(C)=C/C=C/[C@H](C)CO)C(C)[C@@H](O)/C=C/C(C)=C/C(C)=C\[C@H](C)[C](O)/C=C(\C)CCCCO</smiles>

13<smiles>C/C=C\[C@H](C)[C@@H](O)/C=C(\C)CCOC(C)(C)C</smiles>
media-containing assayed compounds. ${ }^{b}$ Calculated by comparing growth on treated vs. untreated media (control).

Figure 2 Arabidopsis V-ATPase assay results for synthetic archazolid fragments 1, 12, and $\mathbf{1 3}$ along with a known V-ATPase inhibitor concanamycin A. Whereas compounds 12 and 13 were inactive, tetrol 1 displayed dose-dependent growth inhibition of etiolated Arabidopsis as an indicator for inhibition of $\mathrm{V}$-ATPase. The results provide further evidence for the importance of properly linked $\mathrm{C}_{7}$ and $\mathrm{C}_{15}$-hydroxyls for archazolid/V-ATPase binding.

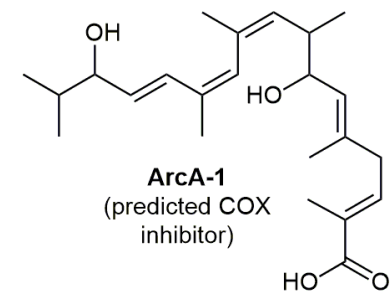

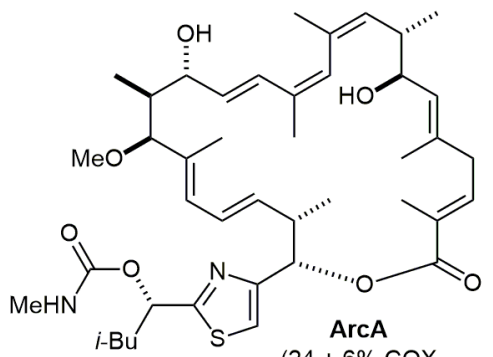

$(24 \pm 6 \% \operatorname{coX}$

inhibition at $10 \mu \mathrm{M}$<smiles>COC(/C(C)=C/C=C/[C@H](C)CO)C(C)[C@@H](O)[C@@H](C)/C=C/C(C)=C/C(C)=C\[C@@H](C)[C@H](O)/C=C(\C)CCCCO</smiles>

Figure 3 Predicted and measured COX inhibitory activity of hypothetical archazolid fragment ArcA-1, archazolid A (ArcA), and synthesized archazolid fragment 1 . The inactivity of 1 suggests certain structural requirements for COX binding (i.e. carboxylic acid or macrocycle).

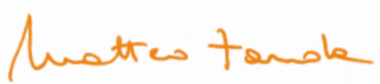




\section{About the authors}

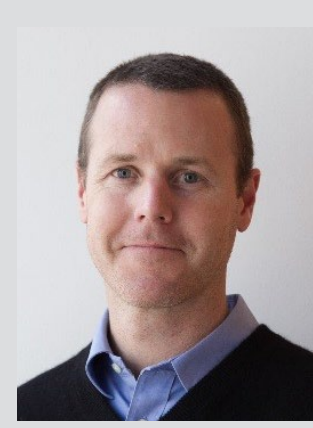

Dr. G. O‘Neil
Gregory O’Neil grew up in New Jersey (USA). He received his B.S. degree in 2002 from Boston College (USA) where he conducted undergraduate research under the guidance of Professor Larry Scott. He then earned a Ph.D. in 2006 from the University of Colorado, Boulder (USA) under the supervision of Professor Andrew Phillips. Before starting his independent career at Western Washington University (USA) in 2008, he received an Alexander-von-Humboldt Postdoctoral Fellowship to work with Professor Alois Fürstner at the Max-Planck Institut für Kohlenforschung (Germany). His research is focused primarily on synthesizing biologically and environmentally compelling natural products.

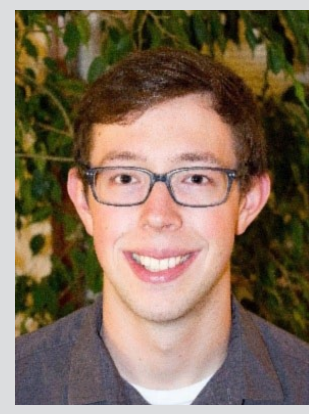

Alexander Craig was born in Olympia (USA) in 1994. He studied biochemistry at Western Washington University where he completed his B.S. degree in 2016, performing research with Professor O’Neil.

\section{A. Graig}

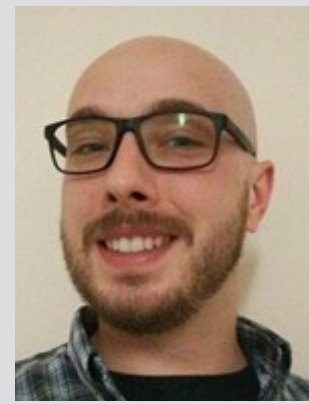

J. Williams II

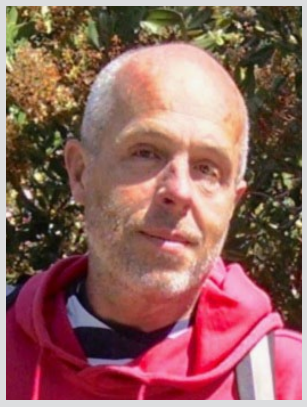

Jeffery Young was born in Berkeley (USA) and received his Ph.D. in 1994 from The Ohio State University (USA) under the guidance of Professor R. Hangarter. In 1994, he joined the lab of Professor M. Sussman at the University of Wisconsin (USA) and studied the role of p-type proton ATPases in plants. His postdoctoral work included the development of Prof. J. Young T-DNA mutagenesis as a reverse genetic tool in Arabidopsis thaliana. He moved to the Biology Department at Western Washington University in 1999 where he currently holds a Full Professor position.

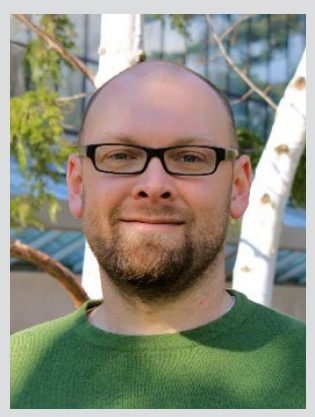

P. Clint Spiegel was born in Oregon (USA), and received his B.S. in Biochemistry and Biophysics from Oregon State University. He completed his Ph.D. studies from the University of Washington (USA) in the lab of Barry Stoddard at the Fred Hutchinson Cancer Research Center in 2004. Following graduate studies, he joined Harry Noller's lab as a Jane Coffin Childs Memorial Foundation Postdoctoral Fellow at the Universi-

Prof. P. C. Spiegel ty of California, Santa Cruz (USA) to study ribosome structure
and function. In 2007, he joined the Chemistry Department at Western Washington University as an Assistant Professor of Chemistry, and in 2015 was promoted to Full Professor. In his independent lab, he employs structural biology approaches to understand the immune response to hemophilia $A$ treatment and takes a biochemical approach to understand the inhibition and activation of ribosome-dependent GTPases. 


\section{Automated Glycan Assembly Using the Glyconeer 2.1 Synthesizer}

PNAS 2017, 114, E3385-E3389

According to Professor Peter H. Seeberger from the Max Planck Institute of Colloids and Interfaces (Potsdam, Germany), synthesizing oligosaccharides has always been one of the great challenges of organic synthesis. "Manipulating monosaccharide protecting groups and designing a strategy for the preparation of oligosaccharides was as much a form of art as it was science," said Professor Seeberger. "Access to these very important molecules was limited because the preparation of oligosaccharides was very challenging and time-consuming, as it requires many purification steps and depends on many variables, which are not trivial to control."

The project of automating the synthesis of oligosaccharides was pioneered by Seeberger and co-workers in 1998, when he started as an assistant professor at MIT (USA). "The idea behind automating the synthesis of oligosaccharides came from the immense success of automated DNA and peptide synthesis," explained Professor Seeberger. "Creating an accessible and reproducible process, while minimizing the number of purification steps, was the goal of the development of the Glyconeer." Professor Seeberger revealed that during the construction of several oligosaccharide synthesizer prototypes - over almost two decades - it became clear that a new synthesizer would not only facilitate the access to oligosaccharides but would also provide online feedback to achieve reproducible results.

Professor Seeberger emphasized: "Many new functionalities have been integrated so that the Glyconeer will meet these requirements. The system was designed to have multiple building block vials to ensure the stability of monosaccharides during synthesis and to allow the synthesis of large oligosaccharides. Multiple solvent and reagent containers were introduced to minimize manipulation of the synthesizer during and in between runs. Furthermore, cooled compartments were integrated in order to guarantee stability of the activating reagents throughout the entire synthesis."

Professor Seeberger said: "In collaboration with engineers and software experts, we designed software that has the capability of controlling all reaction parameters in order to adjust conditions that may vary for each glycosylation. In addition, we added a feedback process that relies on an online detector during the synthesis and set of analytical steps used after synthesis to guarantee the purity of the oligosaccharide."

"We put the Glyconeer to the test by synthesizing oligosaccharides of different complexity to prove that the platform is reliable, reproducible and also flexible," said Professor Seeberger, who concluded: "We are certain that this benchtop synthesizer can find a wide audience in the field of carbohydrate research since it is a straightforward way to synthesize oligosaccharides."

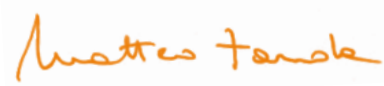


I) Manual Oligosaccharide Synthesis
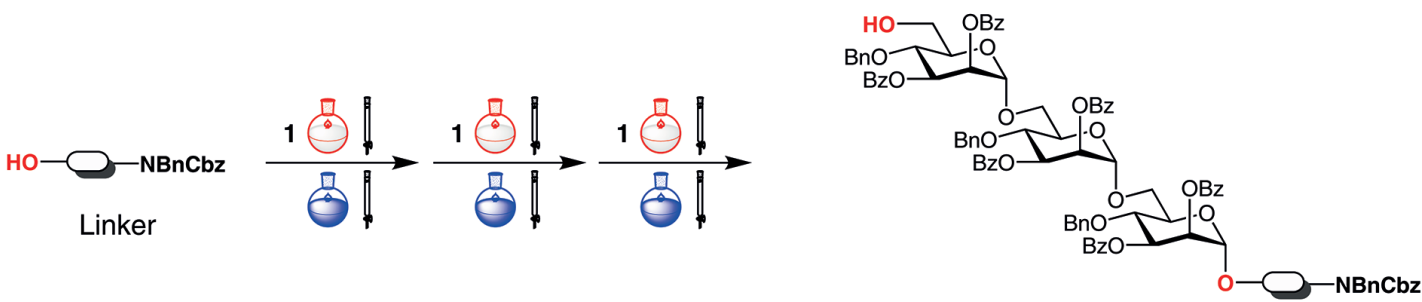

HOC

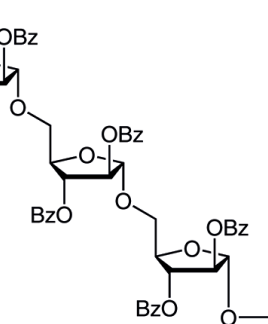

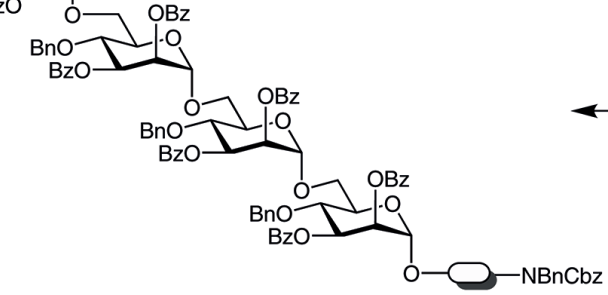

6 glycosylations, 6 deprotections and 12 purifications

II) Automated Oligosaccharide Synthesis

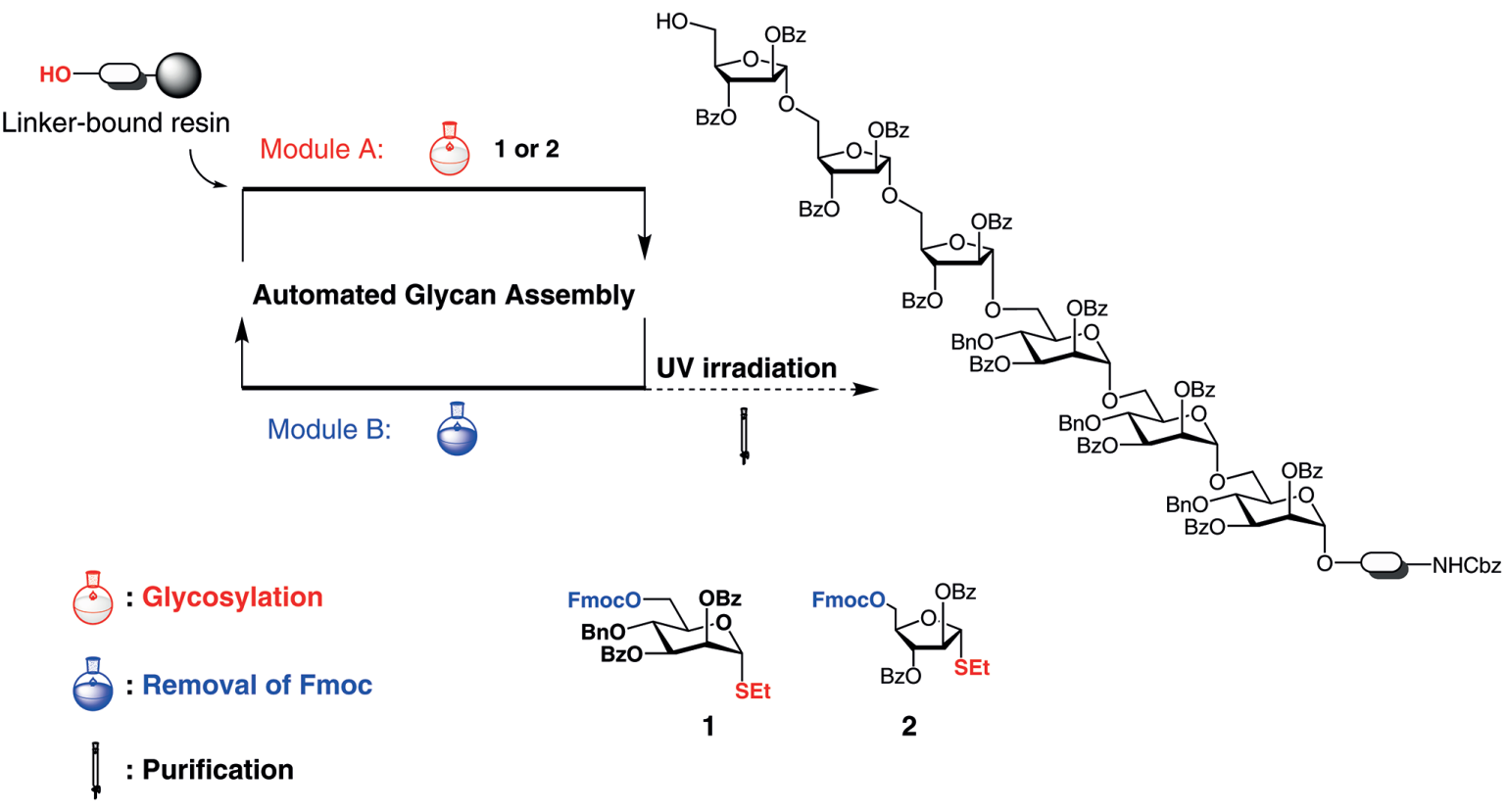

Figure 1 The main differences between I) manual oligosaccharide synthesis, which requires multiple purification steps and is timeconsuming, and II) automated oligosaccharide synthesis, which requires only setting up the synthesizer and applying two modules in an iterative manner 

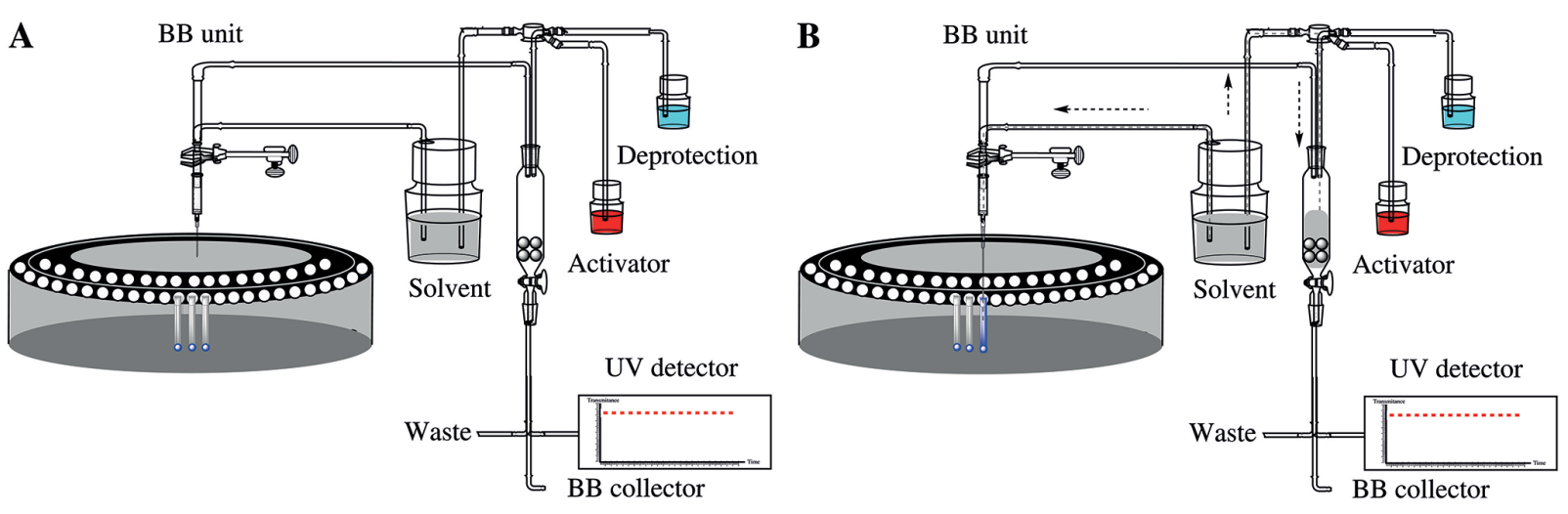

C

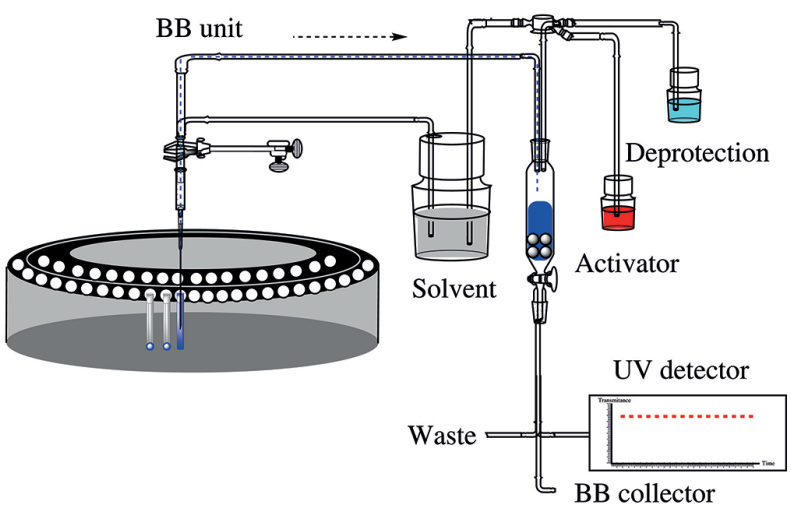

D

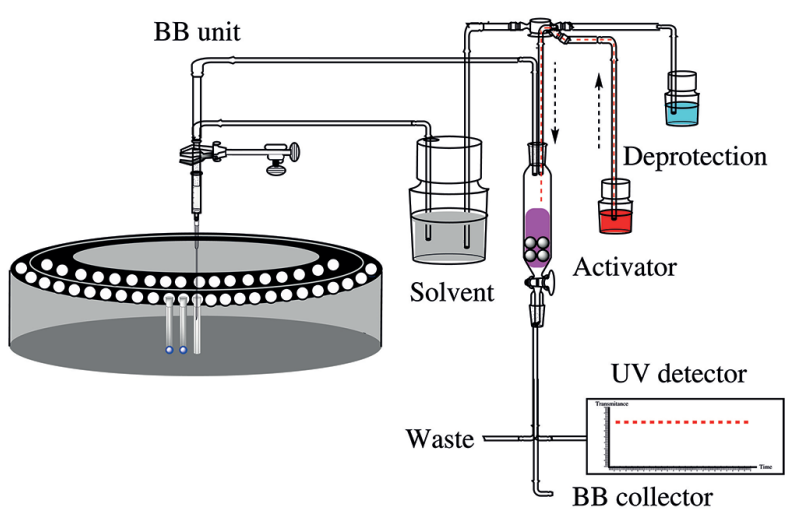

$\mathbf{E}$

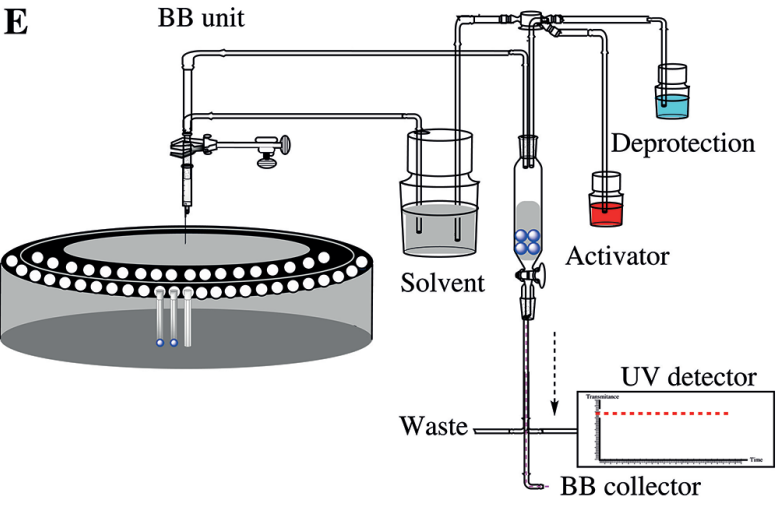

$\mathbf{F}$

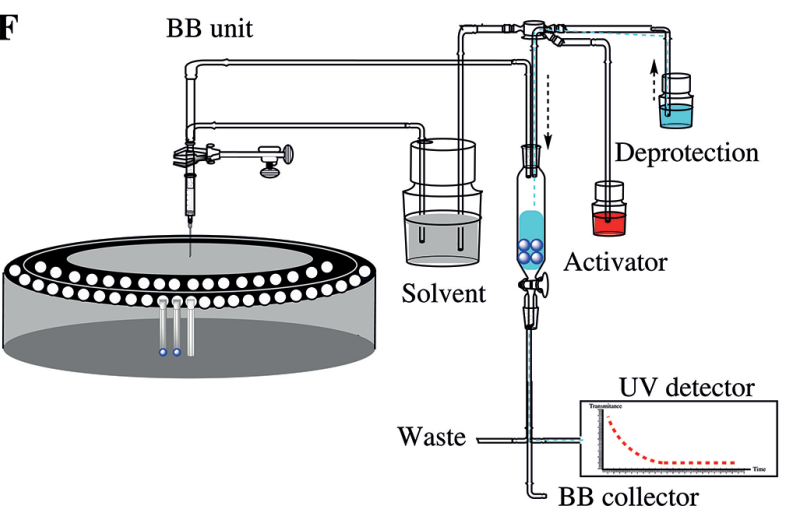

Figure 2 A complete cycle for the elongation and deprotection performed on the synthesizer: A) The system in standby. B) Solvent is added to dissolve the monosaccharide building blocks as the solid support in the reaction vessel (RV) is being washed. C) RV is cooled and the dissolved building blocks (BB) are delivered to the RV. D) Activator is added to the RV to initiate the reaction. E) Glycosylation solution is discarded. F) Deprotection solution is added to RV and washed out after incubation through UV detector to monitor the reaction progress 
About the authors

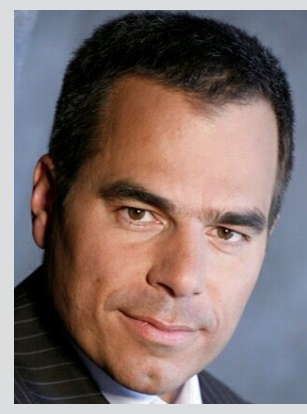

F. Schuhmacher
Frank Schuhmacher was born in Frankfurt (Germany). He was trained as a physics laboratory assistant at Hoechst AG (Germany) and later graduated from his studies in physical technology in Wiesbaden (Germany). After this, he worked as application engineer at Additive in Friedberg (Germany), where he later established a training and education department. In 2000, Frank founded Elexon AG, an independent IT development and training company in Frankfurt (Germany). In 2010, he joined the Max Planck Institute of Colloids and Interfaces in Professor Peter Seeberger's group to complete his Ph.D. studies, which focused on developing automated platforms for oligosaccharide synthesis.

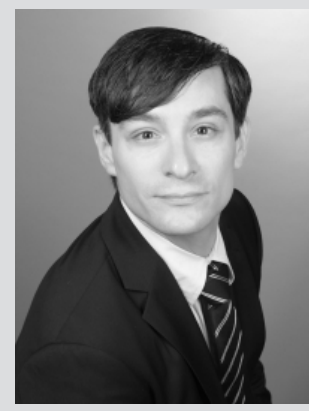

Dr. S. Eller

Steffen Eller was born in Lichtenfels (Germany). He received his undergraduate education at the University of Bayreuth (Germany) and his Ph.D. in chemistry from the same university. He was a postdoctoral fellow at Max Planck Institute of Colloids and Interfaces in Berlin (Germany) in the Biomolecular Systems group of Professor Peter Seeberger. He joined Chemspeed Technologies, a leading provider of high-throughput and high-output research \& development workflow solutions in 2012 as an Automation Chemist. From March to October 2015, he worked as a Workflow Architect before he became Head Workflow/Chemistry/Support and a member of the extended management board in November 2015.

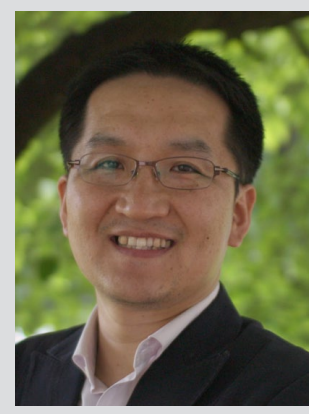

Heung Sik Hahm was born in Sokcho (South Korea). After obtaining a B.S. in chemisty in 2002, and an M.S. in chemistry in 2004 at the Sogang University (South Korea), he was exposed to stem-cell biology using small molecules under the supervision of Professor Sheng Ding at The Scripps Research Institute (TSRI), La Jolla (USA) between 2004 and 2008. After quitting a doctoral program of chemistry and biochemistry at the University of
Colorado, Boulder (USA), he moved to Berlin (Germany) to study for his Ph.D. under the supervision of Professor Peter Seeberger at the Max-Planck-Institute of Colloids and Interfaces (2009 to present). While there, he worked on glycan synthesis using the Automated Glycan Synthesizer and showcased the synthesis of dozens of oligosaccharides including $\alpha$-glucan-containing multiple 1,2-cis-glycosidic linkages, glycosaminoglycans, and a 50mer polymannoside. Furthermore, he participated in the development of the Glyconeer 2.1 Synthesizer as the first commercial glycan synthesizer. At the end of 2015, he joined the laboratory of Professor Ku-Lung (Ken) Hsu as a research scientist at the University of Virginia (USA) to pursue his interests in the area of chemoproteomics and metabolomics using chemical probes.

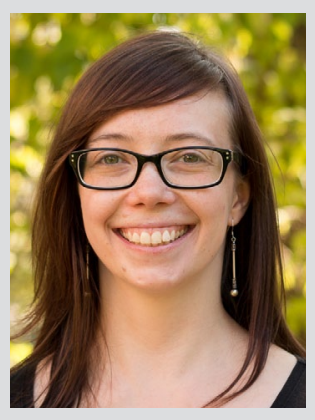

Johanna Hofmann was born in Berlin (Germany). She studied chemistry at the Humboldt-Universität zu Berlin (Germany) and received her diploma in 2012. For her thesis, she investigated a cisplatin-specific antibody and its antibody-antigen complexes by native mass spectrometry. In 2012, she started her Ph.D. at the Fritz Haber Institute of the Max Planck Society and the Free University Berlin (Germany) under the supervision of J. Hofmann

Her research focus is the investigation of Professor Kevin Pagel. Her research focus is the
glycans using ion mobility-mass spectrometry.

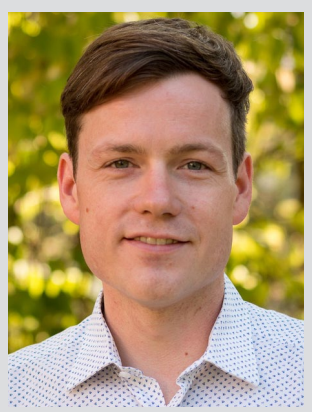

Kevin Pagel was born in Werdau (Germany). He studied chemistry at the University of Leipzig (Germany), where he received his diploma in 2003. Afterwards he moved to the Free University Berlin (Germany) to work on his Ph.D. under the supervision of Professor Beate Koksch. The focus of his thesis, which he successfully defended in 2007, was the design and development of amyloidogenic model peptides. After a brief postProf. K. Pagel doctoral stay at the Free University Berlin, he joined the group of Professor Dame Carol V. Robinson as a fellow of the German Academia of Science Leopoldina, first at the University of Cambridge (UK, 2008-2009) and later at the University of Oxford (UK, 2010). In early 2011, he returned to Berlin to establish his own research. From 2011 until 2014 he worked under the 
supervision of Professor Gerard Meijer as a research associate in the Molecular Physics department of the Fritz Haber Institute of the Max Planck Society. In 2014, he was appointed as Assistant Professor at the Free University Berlin, where he was promoted to Associate Professor in early 2017. In addition, he is affiliated to the Fritz Haber Institute of the Max Planck Society as a guest scientist. His current research is focused on the analysis of biomolecules using ion mobility-mass spectrometry and gas-phase IR spectroscopy, with a special focus on oligosaccharides and amyloidogenic peptides.

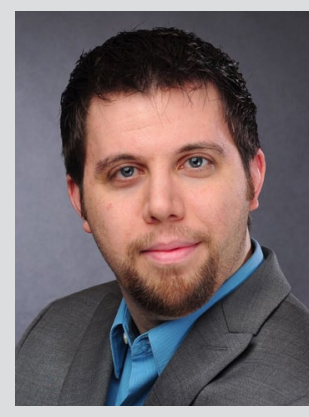

Mark Schlegel, born in Pennsylvania (USA), received his undergraduate education at Moravian College (USA) and subsequently graduated from the University of Pennsylvania (USA), receiving his Ph.D. in the group of Professor Eric Meggers in 2009. After postdoctoral research at the Max Planck Institute of Colloids and Interfaces with Professor Peter Seeberger Dr. M. Schlegel

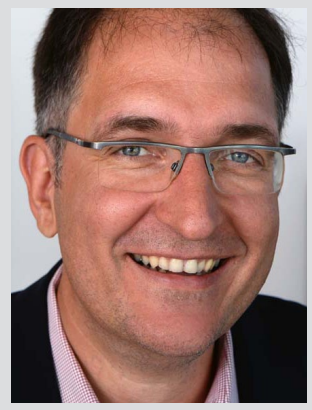

Prof. P. H. Seeberger

Peter H. Seeberger studied chemistry in Erlangen (Germany) and completed his Ph.D. in biochemistry in Boulder, Colorado (USA). After performing research at the Sloan-Kettering Cancer Center in New York (USA), he built an independent research program at MIT (USA) where he was promoted to Firmenich Associate Professor with tenure after just four years. After six years as Professor at ETH Zurich (Switzerland), he assumed positions as Director at the Max-Planck Institute in Potsdam and Professor at the Free University Berlin (Germany). His research covers the glycosciences from chemistry to immunology as well as flow chemistry. GmbH \& CO KGaA (Germany) in 2013 where he worked on the design, development, and implementation of the first commercial Glyconeer in 2014. Currently he is a Senior Scientist at Alnylam Pharmaceuticals (USA) with a focus on developing siRNA-based therapeutics.

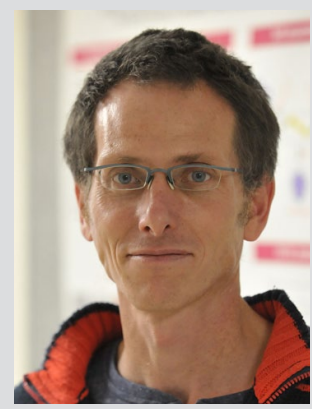

Dr. M. Hurevich
Mattan Hurevich was born in Jerusalem (Israel). He received his undergraduate education at the Hebrew University of Jerusalem (Israel), where he continued for an M.Sc. and a Ph.D. in the group of Professor Chaim Gilon. Mattan joined the oligosaccharide automation team in the group of Professor Peter Seeberger at the Max Planck Institute of Colloids and Interfaces (Germany), where he focused on the development and implementation of several automated platforms. Mattan recently rejoined the Hebrew University as a Senior Lecturer where he continues his research in automated oligosaccharide synthesis. 


\title{
Collective Synthesis of Indole Alkaloids Enabled by Photoredox-Initiated Radical Cascade Reactions
}

\author{
Chem 2017, 2, 803-816
}

Indole alkaloids represent a large and unique family of natural products that are characterized by complex and diverse structures, as well as an important range of bioactivities. Representative molecules such as vinblastine and reserpine have been used as clinical drugs for decades. These features, combined, have rendered the total synthesis of indole alkaloids a topic of great concern for synthetic chemists, the research of which could be traced back to the historic synthesis of reserpine and strychnine in the 1950s by Woodward and co-workers (J. Am. Chem. Soc. 1956, 78, 2023 and references therein).

The group of Professor Yong Qin at Sichuan University (P. R. of China) has a long-standing interest in the synthesis of com-

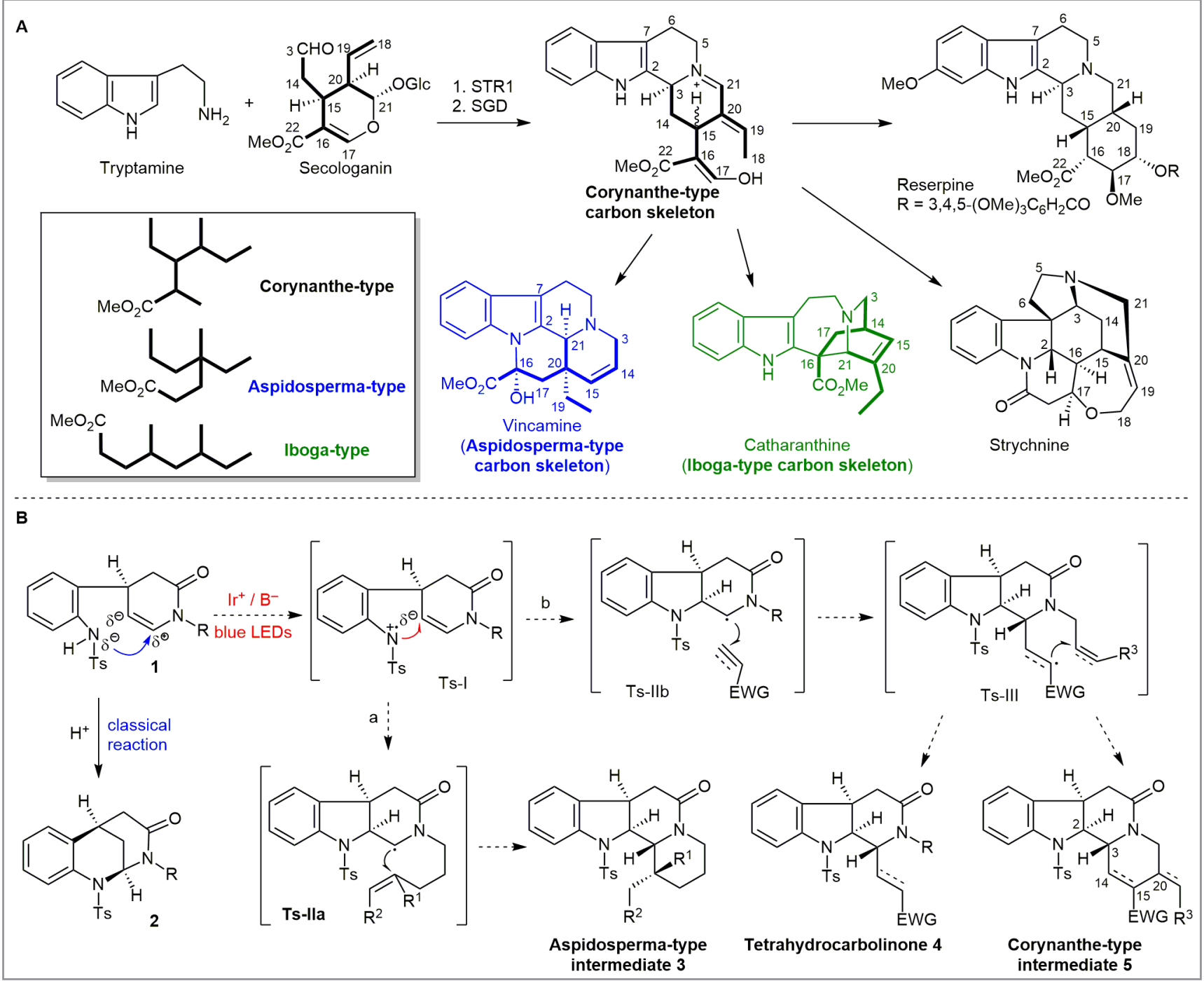

Scheme 1 
plex monoterpenoid indole alkaloids. Previously, the group developed a cyclopropanation strategy (Acc. Chem. Res. 2011, $44,447)$, which has proven to be versatile in the synthesis of several intriguing indole alkaloids, such as communesin $\mathrm{F}$, minfiensine, vincorine, lundurine $A$ and fruticosine. Professor Qin explained: “Biogenetically, all monoterpenoid indole alkaloids are derived from tryptamine and secologanin by strictosidine synthase (STR1) and strictosidine glucosidase (SGD) catalyzed condensation (Scheme 1, A). Based on the carbon skeletons of the monoterpenoid units, these alkaloid natural products could be classified into three major types, namely, corynanthe-, aspidosperma-, and iboga-type alkaloids, which were further expanded to over 15 sub-types and more than 3000 known members." He continued: "In the course of our research, we were ambitious enough to pursue a general strategy that would enable the synthesis of all sub-types of indole alkaloids. Obviously, this would require a breakthrough in developing simple, green, catalytic and asymmetric synthetic methods."

By carefully analyzing the structure of a corynanthe-type core, a common biogenetic precursor of indole alkaloid subtypes, the group envisioned that key disconnections at the $\mathrm{N}-\mathrm{C} 2, \mathrm{C} 3-\mathrm{C} 14$ and $\mathrm{C} 15-\mathrm{C} 20$ bonds would lead back to compound 1 (Scheme 1, B). In a classic reaction pathway, the $\mathrm{N}$ atom in sulfonamide 1 would add to the $\alpha$-position of the enamine double bond due to its electrophilicity, forming the tetrahydroquinoline intermediate 2. "We envisioned that an electron-deficient nitrogen-centered radical (Ts-I; Scheme 1, B) would enable the formation of a $\mathrm{C}-\mathrm{N}$ bond between the electron-donating aniline nitrogen and the $\beta$-carbon of the enamine," said Professor Qin. He continued: “Although this was a big challenge, such a radical could be directly generated via deprotonation and oxidation of a sulfonamide $\mathrm{N}-\mathrm{H}$ bond, which is superior to the classic homolysis of $\mathrm{N}-\mathrm{X}$ functionalities. Accordingly, three types of radical cascade reactions (intra-/intra-molecular, intra-/inter-molecular, and intra-/ inter-/intra-molecular) were also designed to access the aspidosperma-, tetrahydrocarbolinone-, and corynanthe-type skeletons (3, 4, and 5, respectively; Scheme 1, B) starting from sulfonamide 1."

According to their design, the group first examined the generation of a nitrogen-centered radical by direct cleavage of the N-H bond from Ts-protected aniline. Professor Qin said: "Gratifyingly, after extensive experimentation, two PhD students (Xiaobei Wang and Wenfang Qin) detected the formation of an indoline ring when subjecting 1 to the photocatalytic conditions $\left[\mathrm{Ir}(\mathrm{dtbbpy})(\mathrm{ppy})_{2} \mathrm{PF}_{6}(0.5 \mathrm{~mol} \%), \mathrm{KHCO}_{3}\right.$ (5 equiv), THF, blue LEDs]. Inspired by this preliminary result,

A

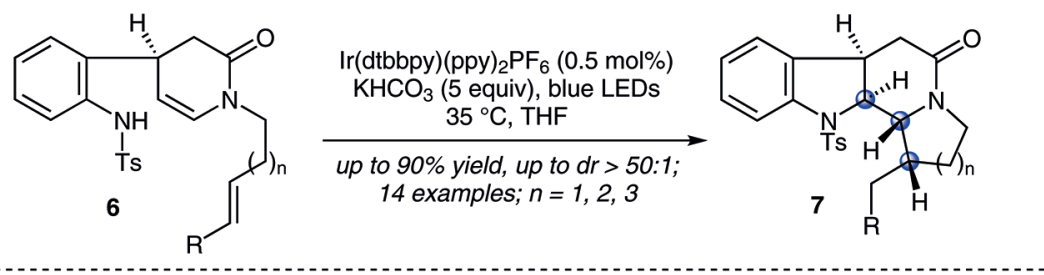

B
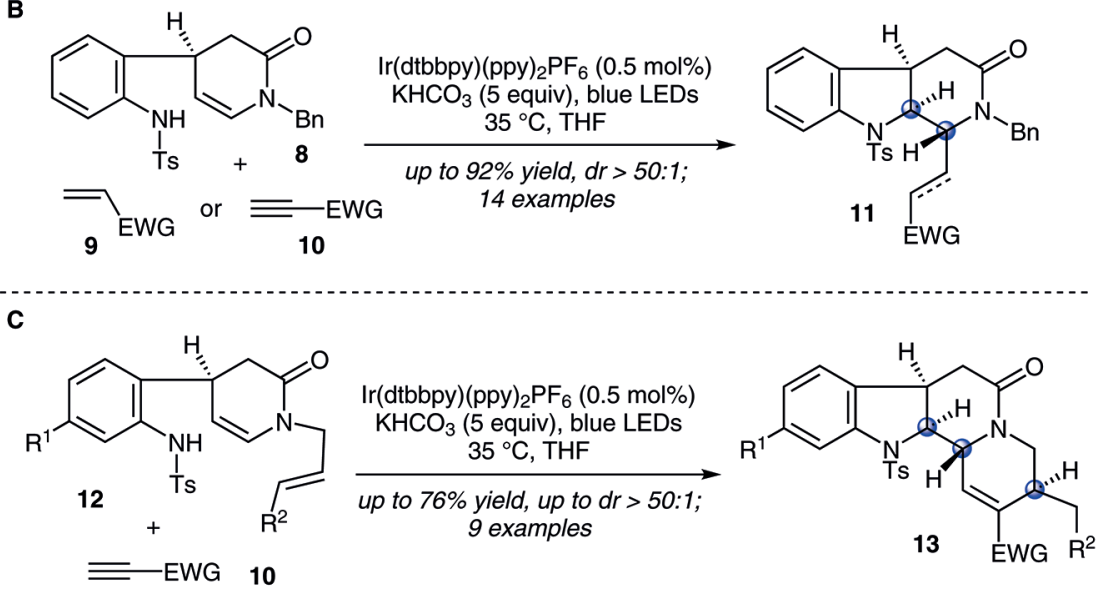

\section{Scheme 2}


three types of radical cascade reactions were carried out as illustrated in Scheme 2." Treating substrate 6 with the optimized reaction conditions led to the formation of aspidosperma derivatives 7. Reaction of $\mathbf{8}$ in the presence of an external radical acceptor ( $\mathbf{9}$ or $\mathbf{1 0}$ ) yielded tetrahydrocarbolinone derivatives 11, and an intra-/inter-/intra-molecular cascade occurred using $\mathbf{1 2}$ and $\mathbf{1 0}$ as substrates to afford tetracyclic corynanthe-type intermediates $\mathbf{1 3}$. All these radical cascade reactions proceeded efficiently to construct multiple $\mathrm{C}-\mathrm{N}$ and $\mathrm{C}-\mathrm{C}$ bonds and rapidly establish molecular complexity in moderate to excellent yields. Notably, excellent control of diastereoselectivity of the newly formed stereogenic centers was observed in most of the examples.
Professor Qin remarked: "Having the radical cascade methodology established, we next explored its application to the total synthesis of indole alkaloids (Scheme 3). By careful and precise design of the structure of substrates, our group succeeded in synthesizing 33 indole alkaloids belonging to four sub-types (eburnamine-vincamine, yohimbine, corynanthe, and heteroyohimbine) in 6-14 steps using the radical cascade as a key reaction." He continued: "Of note, all these key radical cascades were performed on decagram scales. While excellent stereoselectivity was observed at positions C2 and C3 (or C21 in aspidosperma-type intermediates $15 \mathrm{a} / \mathrm{b}$ ), generation of stereochemical divergence at distal sites such as C15 and C20 in the products provided us good opportunities to synthesize corresponding naturally differentiated indole alkaloids."

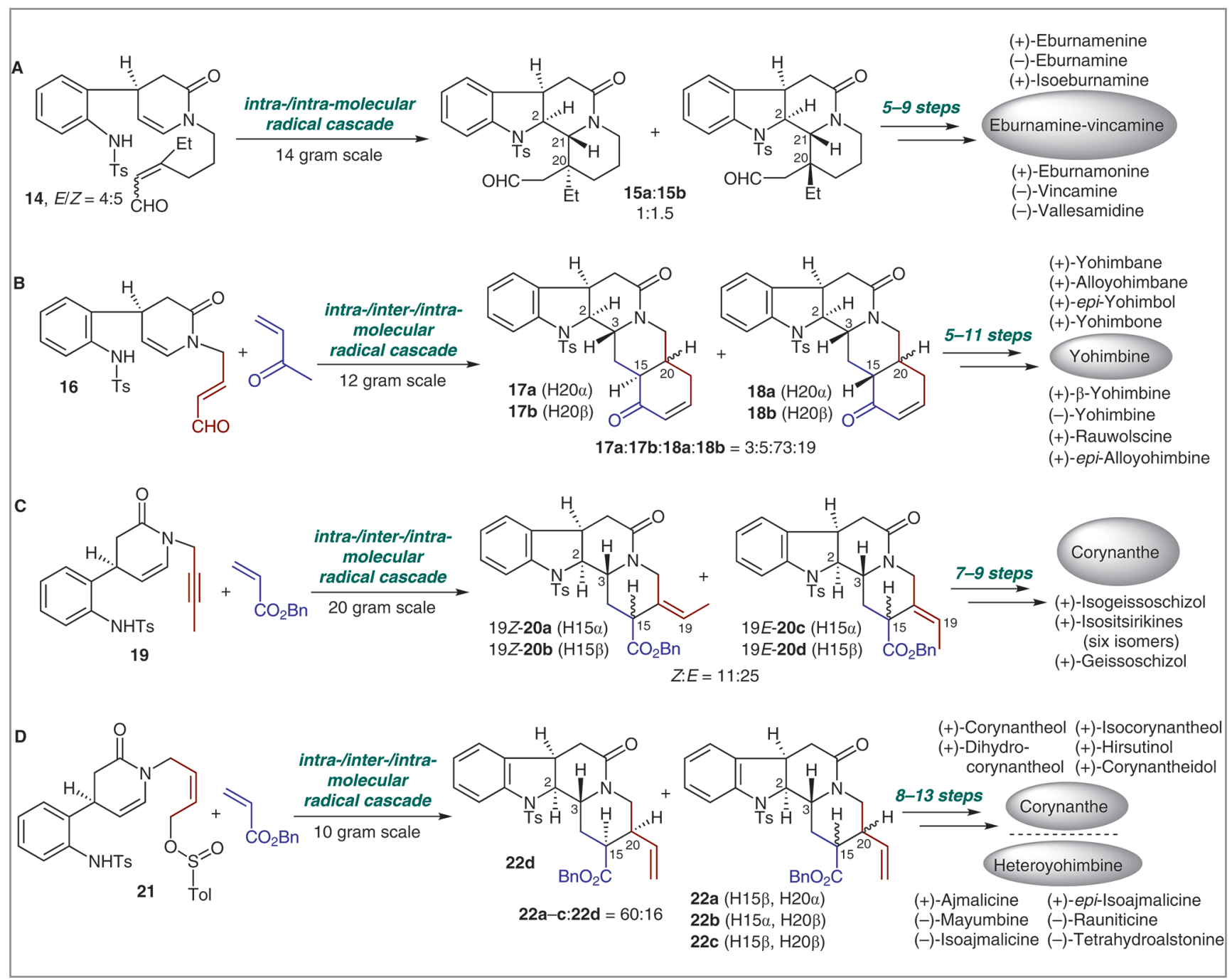

Scheme 3 
"To summarize, a target-oriented synthesis program which aimed at a large collection of natural products has prompted us to develop an innovative synthetic method," said Professor Qin. "This photoredox-induced protocol provided mild and direct generation of a nitrogen-centered radical via deprotonation and oxidation of a sulfonamide $\mathrm{N}-\mathrm{H}$ bond. Subsequent cascade reactions not only reversed the conventional reactivity between two electron-donating amine and enamine groups, but also allowed efficient access to libraries of chiral and multiple-ring-fused tetrahydrocarbolinones." Professor Qin concluded: "Collective synthesis of 33 indole alkaloids has thus been accomplished by employing this simple, mild, and scalable method as a key step. This powerful strategy is expected to facilitate the synthesis of more types of indole alkaloids and associated analogues."

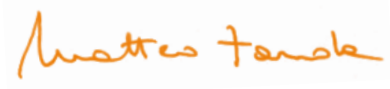

\section{About the authors}

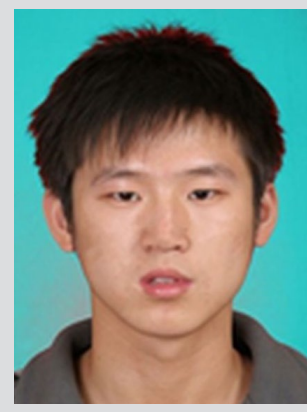

X. Wang

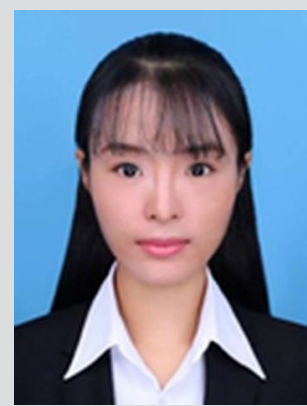

W. Qin

Xiaobei Wang was born in Anhui Province (P. R. of China) and obtained his B.Sc. degree in pharmacy from Sichuan University (P. R. of China) in 2012. In the same year, he joined the group of Professor Yong Qin at Sichuan University to pursue his Ph.D. degree. His research focuses on the total synthesis of complex natural products, especially biologically active indole alkaloids.

Wenfang Qin was born in Hebei Province (P. R. of China). She received her B.Sc. degree in pharmacy at Chongqing University (P. R. of China) in 2012. In the same year she joined the group of Professor Yong Qin at Chongqing University to conduct her Ph.D. studies. Her research focuses on the total synthesis of natural products and methodology studies.

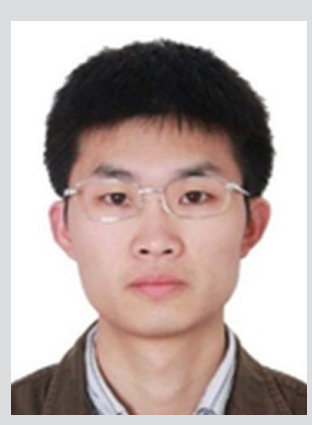

Dr. X.-Y. Liu

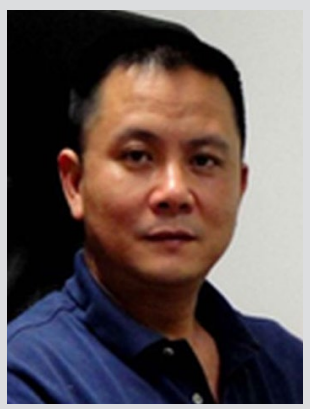

Prof. Y. Qin
Xiao-Yu Liu received his Ph.D. degree in 2012 under the supervision of Professor Feng-Peng Wang at Sichuan University (P. R. of China). After conducting postdoctoral research in the group of Professor David Y.-K. Chen at Seoul National University (South Korea), he joined the faculty of Sichuan University in 2014 to work with Professor Yong Qin. His research interests include the target- and diversity-oriented synthesis based on complex natural products.

Yong Qin received his B.Sc. degree from Yunnan University (P. R. of China) in 1989 and his Ph.D. from the Institute of Chemistry, Chinese Academy of Sciences (Beijing, P. R. of China) in 1995. From June 1995 to August 1996, he worked at the Chengdu Institute of Organic Chemistry (P. R. of China) as an Assistant and Associate Professor. From August 1996 to August 2000, he worked with Professor Martin E. Kuehne as a postdoctoral associate at the University of Vermont (USA). Then, he moved to San Diego (USA) and worked as a research scientist at Triad Therapeutics Inc. In 2003, he joined the faculty of West China School of Pharmacy, Sichuan University (P. R. of China) as a full Professor. His research has been focused on the total synthesis of bioactive natural products and medicinal chemistry. 


\section{Young Career Focus: Professor Alexander J. Grenning (University of Florida, USA)}

\section{Background and Purpose. SYNFORM regularly meets young up-and-coming researchers who are} performing exceptionally well in the arena of organic chemistry and related fields of research, in order to introduce them to the readership. This Young Career Focus presents Professor Alexander J. Grenning (University of Florida, USA).

\section{Biographical Sketch}

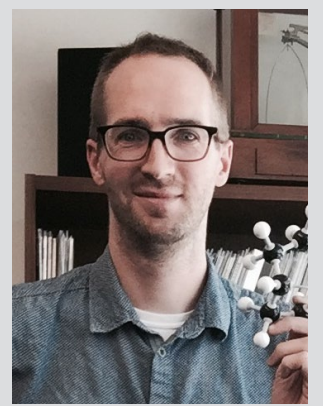

Prof. A. J. Grenning
Alex Grenning is from the northern suburbs of Chicago (USA). He received his B.A. degree from Lake Forest College (USA) under the research supervision of Dr. William B. Martin in 2007. He received his Ph.D. in Chemistry in 2012 from the University of Kansas (USA) under the guidance of Professor Jon A. Tunge where he developed various decarboxylative and deacylative allylation reactions. In 2012, he moved to Boston University (USA) to work with Professor John A. Porco on complex molecule synthesis, most notably the development of new routes to polyprenylated acylphloroglucinol (PPAP) natural products and analogues. Alex's independent career began in the summer of 2014 when he joined the faculty in the Department of Chemistry at the University of Florida in Gainesville (USA).

His broad research goal is to simplify complex molecule synthesis through the invention of novel chemical methodologies and strategies and to discover natural product based chemotherapeutics.

Other interests include rock n' roll, guitars, record collecting, microbrews, billiards, long boarding, biking, and of course, entertaining his little girls ( $\sim 3$ years old and $\sim 1$ year old as of June 2017).

- Visit the Grenning Lab homepage: www.grenninglab.com

- Follow Alex on Twitter: OChem_Grenning

\section{INTERVIEW}

SYNFORM What is the focus of your current research activity?

Prof. A. J. Grenning My group's overall research goal is to simplify access to complex terpenoid natural products and analogues. To do this, we are developing methods to multifunctionalize Knoevenagel adducts.

\section{SYNFORM When did you get interested in synthesis?}

Prof. A. J. Grenning It was while participating in the "Molecule of the Semester" meetings held jointly between the Tunge, Hanson, Aube, and other labs at The University of Kansas. I believe these meetings have their origin from Professor Trost's group: Student teams devise total synthesis plans, present their ideas, and then get eaten alive by the faculty! It was challenging, but I learned a lot and it got me hooked on synthesis!

SYNFORM What do you think about the modern role and prospects of organic synthesis?

Prof. A. J. Grenning De novo synthesis is often the only method to get a hold of certain bioactive natural products and their analogues. We must continue to become more proficient at complex molecule synthesis.

SYNFORM Your research group is active in the area of synthetic methodology and bioorganic/medicinal chemistry. Could you tell us more about your research and its aims?

Prof. A. J. Grenning We are devising a simple and tunable platform for complex terpenoid natural product and analogue synthesis. By the nature of our goal, it must be achieved from inexpensive and abundant starting materials using simple 


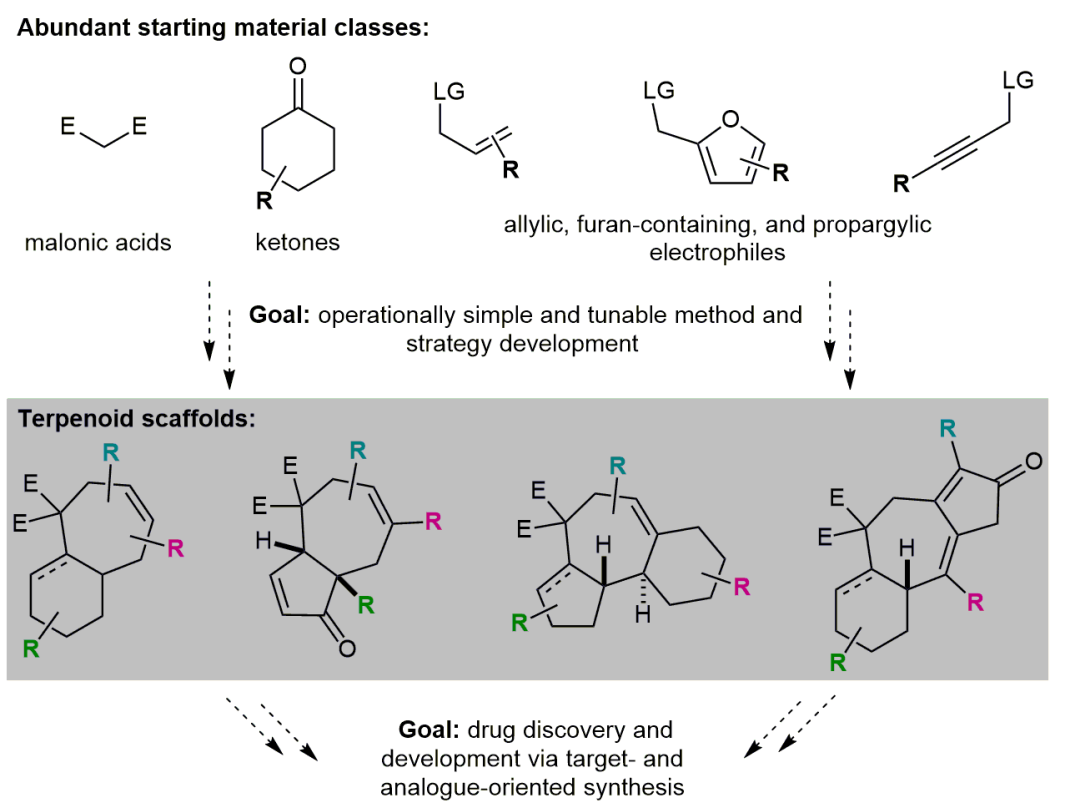

Figure 1

chemical transformations. Through our efforts, we will establish a synthetic platform for natural product and analogue synthesis that is user-friendly and therefore, hopefully, adopted by those interested in drug discovery.

SYNFORM What is your most important scientific achievement to date and why?

Prof. A. J. Grenning Although it can feel like "drops in the bucket," we are slowly but steadily making progress toward a "unified terpenoid synthesis strategy." I would recommend the following two papers as introductions to our research program:

(1) S. K. Scott, A. J. Grenning "An Enyne Cope Rearrangement Enables Polycycloalkane Synthesis from Abundant Starting Materials" Angew. Chem. Int. Ed. 2017, 56, 8125.

(2) O. Lahtigui, F. Emmetiere, W. Zhang, L. Jirmo, S. Toledo-Roy, J. C. Hershberger, J. M. Macho, A. J. Grenning "Assembly of Terpenoid Cores by a Simple, Tunable Strategy" Angew. Chem. Int. Ed. 2016, 55, 15792.

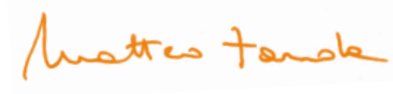




\section{Coming soon}

\section{- Literature Coverage}

Asymmetric Silver-Catalyzed Intermolecular Bromotrifluoromethoxylation of Alkenes with a New Trifluoromethoxylation

\section{Reagent}

- Literature Coverage

Unique Physicochemical and Catalytic Properties Dictated by the $\mathrm{B}_{3} \mathrm{NO}_{2}$ Ring System

\section{- Literature Coverage}

\section{Nickel-Catalyzed C-Alkylation of Nitroalkanes with Unactivated Alkyl lodides}

\section{Further highlights}

\section{Synthesis Review: Synthesis of $\alpha$-Amino Esters via $\alpha$-Nitro} or $\alpha$-Oxime Esters

(by Y. L. Janin and co-workers)

Synlett Account: New Reaction Mode in CarboxylateDirected C-H Functionaliza-tions: Carboxylates as Deciduous Directing Groups (by A. Biafora, L. J. Gooßen)

\section{Synfacts Synfact of the Month in category "Metal-Catal-} yzed Asymmetric Synthesis and Stereoselective Reactions": Asymmetric CuH-Catalyzed Coupling Reaction to Access Chiral Ketones
Editor

Matteo Zanda, NRP Chair in Medical Technologies, Institute of Medical Sciences, University of Aberdeen, Foresterhill, Aberdeen, AB25 2ZD, UK and

C.N.R. - Istituto di Chimica del Riconoscimento Molecolare

Via Mancinelli, 7, 20131 Milano, Italy

Editorial Assistant: Alison M. Sage

synform@outlook.com; fax: +3902 23993080

Editorial Office

Managing Editor: Susanne Haak,

susanne.haak@thieme.de, phone: +497118931786

Scientific Editor: Michael Binanzer,

michael.binanzer@thieme.de, phone: +49 7118931768

- Scientific Editor: Stefanie Baumann,

stefanie.baumann@thieme.de, phone: +49 7118931776

Scientific Editor: Selena Boothroyd,

selena.boothroyd@thieme.de

Assistant Scientific Editor: Kathrin Ulbrich,

kathrin.ulbrich@thieme.de, phone: +49711 8931785

Senior Production Editor: Thomas Loop.

thomas.loop@thieme.de, phone: +497118931778

Production Editor: Thorsten Schön,

thorsten.schoen@thieme.de, phone: +49711 8931781

Production Manager: Sophia Hengst,

sophia.hengst@thieme.de, phone: +49 7118931398

Editorial Assistant: Sabine Heller,

sabine.heller@thieme.de, phone: +49 7118931744

- Senior Marketing Manager: Julia Stötzner,

julia.stoetzner@thieme.de, phone: +497118931771

- Postal Address: Chemistry Journals, Editorial Office, Georg Thieme Verlag KG,

Rüdigerstraße 14, 70469 Stuttgart, Germany,

Homepage: www.thieme-chemistry.com

Publication Information

Synform will be published 12 times in 2017 by Georg Thieme Verlag KG, Rüdigerstraße 14, 70469 Stuttgart, Germany, and is an additional online service for Synthesis, Synlett and Synfacts.

\section{Publication Policy}

Product names which are in fact registered trademarks may not have been specifically designated as such in every case. Thus, in those cases where a product has been referred to by its registered trademark it cannot be concluded that the name used is public domain. The same applies as regards patents or registered designs.

Ordering Information for Print Subscriptions to Synthesis, Synlett and Synfacts The Americas: Thieme Publishers New York, Thieme Medical Publishers, Inc., 333 Seventh Avenue, New York, NY 10001, USA.

Via e-mail: customerservice@thieme.com

Via website: www.thieme-chemistry.com

Phone: +1 212760 0888; Fax: +1 2129471112

Order toll-free within the USA: +1 8007823488

Europe, Africa, Asia, and Australia: Thieme Publishers Stuttgart, Georg Thieme Verlag KC, Rüdigerstraße 14, 70469 Stuttgart, Germany.

Via e-mail: customerservice@thieme.de

Via website: www.thieme-chemistry.com

Phone: +497118931421 ; Fax + 497118931410

Current list prices are available through www.thieme-chemistry.com.

Online Access

The online versions of Synform as well Synthesis, Synlett, Synfacts and SynOpen are available through www.thiemeconnect.com/products/ejournals/journals) where it is als possible to register for a free trial account. For information on multi-site licenses and pricing for corporate customers as well as backfiles, please contact our regional offices:

The Americas: esales@thieme.com, phone: +1 2125844695

Europe, Africa, Asia, and Australia: eproducts@thieme.de, phone: +49 7118931407 India: eproducts@thieme.in, phone +911204556600

Japan: brhosoya@poplar.ocn.ne.jp, phone+81333580692

Manuscript Submission to Synthesis, Synlett, and SynOpen Manuscript submissions will be processed exclusively online via

http://mc.manuscriptcentral.com/synthesis, http://mc.manuscriptcentral.com/synlett and http://mc.manuscriptcentral.com/synopen, respectively. Please consult the Instructions fo Authors before compiling a new manuscript. The current version and the Word template for manuscript preparation are available for download at www.thieme-chemistry.com.

Copyright

This publication, including all individual contributions and illustrations published therein, is legally protected by copyright for the duration of the copyright period. Any use, exploitation or commercialization outside the narrow limits set by copyright legislation, without the publisher's consent, is illegal and liable to criminal prosecution. This applies to translating, copying and reproduction in printed or electronic media forms (databases, online network systems, Internet, broadcasting, telecasting, CD-ROM, hard disk storage, microcopy edition, photomechanical and other reproduction methods) as well as making the material accessible to users of such media (e.g., as online or offline backfiles).

Copyright Permission for Users in the USA

Authorization to photocopy items for internal or personal use, or the internal or person use of specific clients, is granted by Georg Thieme Verlag KG Stuttgart · New York for libraries and other users registered with the Copyright Clearance Center (CCC) Transactional Reporting Service, provided that the base fee of US $\$ 25.00$ per copy of each articl is paid directly to CCC, 22 Rosewood Drive, Danvers, MA 01923, USA, 0341-0501/02.
SYNFORM issue 2017/10 is available from September 18, 2017 at www.thieme-connect.com/ejournals 